\title{
Fanpages de viagem - Uma análise sobre o Facebook como suporte da memória coletiva ${ }^{1}$
}

\section{Andréa Braga Santiago de Sá}

Graduada em Comunicação Social pela Universidade Federal de Roraima (2009). Especialista em Jornalismo Digital pela Universidade Internacional de Curitiba (Uninter). Jornalista concursada da Universidade Federal de Roraima (UFRR) desde 2012. Mestranda em Comunicação na Universidade Paulista (Unip). E-mail: andreasaj7@gmail.com

\section{Barbara Heller}

Mestre em Ciências da Comunicação pela Universidade de São Paulo (1990). Doutora em Teoria Literária pela Universidade Estadual de Campinas (1997). Pós-doutora em Comunicação pela Universidade Metodista (2011), e pela Escola de Comunicação e Artes da USP (2015). Docente e Vice-coordenadora do Programa de Mestrado e Doutorado em Comunicação da Universidade Paulista (Unip). E-mail: b.heller.sp@gmail.com
Resumo: Estudar se e como se manifestam as narrativas de memórias no Facebook se faz fundamental para pensarmos os relatos de viagem como fonte documental. O presente artigo tem a proposta de discutir teoricamente se as fanpages (páginas de fãs) disponíveis no Facebook são um suporte atual de memória coletiva. Foram observadas as fanpages Por Uma Vida Sem Arrependimentos e 100 Frescura e 1000 destinos, selecionadas graças ao elevado número de postagens e seguidores no ano de 2017. Para tanto, nos apoiamos em Beatriz Sarlo, Priscila Perazzo e Maurice Halbwachs para as reflexões teóricas. Avaliamos que essas postagens caracterizam-se como narrativas da memória na contemporaneidade, graças à tecnologia que envolve as mídias digitais e as redes sociais.

Palavras-chave: Memória coletiva; Narrativas de viagem; Fanpages.

\section{Travel fan pages - An analysis about Facebook as a collective memory support}

Abstract: Studying whether and how memory narratives are expressed on Facebook is substantial to consider if travel reports are documental sources. This article proposes to discuss, theoretically, if fan pages available on Facebook are a current support of collective memory. The fan pages Por Uma vida Sem Arrependimentos and 100 Frescura e 1000 destinos were chosen due to their high number of posts and followers, in 2017. For this purpose, we followed Beatriz Sarlo, Priscila Perazzo and Maurice Halbwach's theoretical reflections. We concluded that these posts are characterized as memory narratives in the contemporary world, thanks to the technology involving digital media and social networks.

Keywords: Collective memory; Travel narratives; Fan pages.

\footnotetext{
${ }^{1}$ Versão atualizada do artigo aprovado no 40 ㅇ Congresso Brasileiro de Ciências da Comunicação (Intercom), na Universidade Positivo, Curitiba, de 4 a 9 de setembro de 2017.
} 


\section{Introdução}

Quando, em 1500, os portugueses se depararam com o Brasil e as diversas nações indígenas que compunham a população local, trataram de produzir o primeiro documento escrito sobre as novas terras: a Carta do Descobrimento, de Pero Vaz de Caminha (CASTRO, 2003). Considerada pelos historiadores como a certidão de nascimento do novo país, a carta tratava das impressões do escriba sobre a fauna, a flora, a população local e a travessia do oceano Atlântico. Hoje em dia, tal documento, bem como as cartas de Cristóvão Colombo, Américo Vespúcio e de outros viajantes enviados pelas cortes europeias às colônias, permitem interpretar a visão eurocêntrica sobre o Novo Mundo e a forma violenta como a cultura europeia foi imposta aos habitantes desses territórios.

Castro (2003) denomina de "literatura de testemunho" esse tipo de texto e esclarece que ela se manifesta em dois gêneros textuais predominantes: cartas ou diários.

É importante destacar que, apesar de esses conhecidos relatos de viagem terem sido aceitos oficialmente como fonte documental, há uma discussão entre os historiadores se devem ser entendidos como tais na contemporaneidade. Schemes (2013) ressalta que para um relato de viagem ser considerado documento, se faz necessário situar cada deslocamento com o contexto histórico imediato em que ele está inserido. Outro aspecto importante é buscar compreender a trajetória do viajante e o conhecimento prévio que ele tem do lugar de destino.

Já Junqueira (2011) reconhece os relatos de viajantes como corpus documental, mas pondera que são pouco definidos e que é necessário considerarmos em qual etapa da viagem o relato foi escrito, fator que determina diferenças no resultado final.

Independentemente de seu conteúdo ser considerado oficial ou não, é certo que esses relatos ajudaram a "des-cobrir" um mundo ainda "en-coberto" para muitas pessoas, influenciando, assim, a visão construída acerca dele. Os relatos de viagem também serviram e servem como fontes importantes para estudos que procuram entender os fenômenos do passado e suas relações com o presente. Enfim, são elementos plenamente formados por e para memórias.

Inspirados pela noção de que a memória coletiva se manifesta por intermédio de diversos formatos de registro, observamos que no contexto contemporâneo a internet tem revolucionado as maneiras por meio das quais as pessoas podem se manifestar acerca de suas experiências, motivando, assim, as ciências humanas a se reinventarem e abrirem espaço para adaptações metodológicas e novos paradigmas. Os relatos e cartas do passado, usados como registros históricos de uma memória que foi compartilhada e se tornou coletiva, também vêm sendo afetados pela mudança tecnológica e nessa discussão, mais especificamente, pela internet.

Dentre as diferenças atuais, destacamos que viajantes, desde que encontrem conexões gratuitas com a internet, contam com um espaço instantâneo para o relato das suas experiências, percepções e descrições de viagem. Para isso, fazem uso de redes sociais como Facebook, Instagram (mais voltado para fotos) e Snapchat (veiculação de vídeos), produzindo um espaço privilegiado para discussões sobre memória, narrativas de viagens e interação.

A nossa proposta, por meio deste texto, é produzir algumas reflexões teóricas sobre as narrativas de viagem no Facebook, entendendo-as como registros contemporâneos de uma memória coletiva. Partimos da seguinte questão: fanpages de viajantes que disponibilizam seus relatos servem como corpus para o estudo de memórias coletivas?

Acreditamos que a internet e, principalmente, as redes sociais têm mudado a forma como os jovens lidam com os processos da memória, sendo fundamental compreendermos como ocorrem. Para isso precisamos de direcionamentos teóricometodológicos que deem conta do fenômeno.

É importante destacar que selecionamos como corpus as narrativas de viagens produzidas por duas jovens mochileiras em suas fanpages no Facebook, sendo elas 
Pâmela Marangoni (produtora da página 100 frescura e 1000 destinos) e Dwanne Almeida (responsável pela produção da página Por Uma Vida Sem Arrependimentos). Ainda que este seja um texto essencialmente teórico, é preciso levar em consideração essas fanpages, por ser este o contexto que permeia nossas reflexões.

Pâmela Marangoni, 30 anos, apresenta sua página com a seguinte chamada: "Acompanhe o dia a dia de uma menina do interior do MS que resolveu viver a vida de uma maneira diferente: viajando de carona/bike e trabalhando pelo caminho" (100 FRESCURA..., 2013). A fanpage conta atualmente com 44.136 seguidores (consulta realizada no dia 28 de julho de 2017).

As postagens, em sua maioria, são acompanhadas de fotos dos lugares que a viajante visita, assim como das pessoas que a hospedam durante seu percurso. Com certa frequência, também são colocados vídeos de momentos em que a mochileira desfruta em suas viagens. Frases motivacionais são costumeiramente utilizadas.

A viajante Dwanne de Almeida, 25 anos, é autora da página intitulada Por Uma Vida Sem Arrependimentos, e assim resume sua experiência: "Diário da Dw 'Dû' que atravessa o Brasil de carona, contando histórias com $R \$ 1,60$ no bolso rs, fazendo amigos e se divertindo intensamente" (POR UMA VIDA..., 2015).

A página possui atualmente 4.788 seguidores e conta com características bem semelhantes às da viajante Pâmela Marangoni. No entanto, o que a diferencia é a maior predominância de vídeos e a menor visibilidade dada aos "perrengues" de viagem.

\section{Narrativas e memórias}

Antes de discorrermos sobre testemunhos, é importante falarmos brevemente a respeito do hábito da narrativa, já que assim o fazem as viajantes observadas para a elaboração deste artigo. Elas narram as suas aventuras de viagem, criando uma espécie de novela da vida real acompanhada por uma grande quantidade de seguidores.

Para Walter Benjamin:

A experiência que passa de pessoa é a fonte a que recorrem todos os narradores. $\mathrm{E}$, entre as narrativas escritas, as melhores são as que menos se distinguem das histórias orais contadas pelos inúmeros narradores anônimos. Entre estes, existem dois grupos que se interpenetram de múltiplas maneiras. A figura do narrador só se torna plenamente tangível se temos presentes esses dois grupos. "Quem viaja tem muito que contar", diz o povo, e com isso imagina o narrador como alguém que vem de longe. Mas também escutamos com prazer o homem que ganhou honestamente sua vida sem sair do país e que conhece suas histórias e tradições. (1994: 198)

Nesse misturar de narrativas com memórias, João Canavilhas (2004) traça um breve panorama ao contar que, inicialmente, a memória coletiva dependia do processo biológico interno de determinados indivíduos que, por serem detentores de um determinado dom, funcionavam como guardiões da memória social do grupo. Segundo ele, com a passagem da oralidade à escrita, ocorre a dessacralização da memória enquanto processo biológico, e a consequente exteriorização e autonomização da memória, a qual materializa-se em suportes manuscritos e inscrições em monumentos.

Maurice Halbwachs (1990) afirma que a memória é um elemento essencial da nossa identidade. Ele a divide em duas categorias: uma individual, autobiográfica, e outra social, externa, histórica. A primeira está focada em um único ser e a segunda baseia-se nas lembranças coletivas. Em relação à primeira memória, apesar de individual, ela é também coletiva, por ser alterada conforme o indivíduo dialoga com outros integrantes da sociedade, o que ocorre a partir de referências e lembranças 
da ambiência em que se está inserido. Exemplos de como isso acontece são os livros, conversas e o contato com relatos, cartas e diários de viagens publicados.

Acerca da segunda memória, a social, ela pode aparecer solidificada e perpetuada a partir de relatos aos quais se recorre para reforçar ou enfraquecer, e também completar, o que sabemos sobre algum evento. É importante considerar que, segundo Halbwachs, o primeiro testemunho ao qual recorreremos é o nosso, criando um processo dinâmico entre a memória e esses registros. Como exemplo, podemos citar novamente o retrato que temos em nosso imaginário coletivo sobre a impressão do Brasil apresentada por Pero Vaz de Caminha na carta a Portugal. Obviamente, outros relatos ajudam a formar a imagem coletiva que temos do país, inclusive as interpretações contemporâneas.

Hoje a visão que formamos sobre o episódio está transmutada e se apresenta de maneira polifônica. As lembranças não são mais as de um país descoberto, e sim de uma terra invadida por meio de muitas atrocidades contra diversos povos nativos. No entanto, os relatos permanecem e se sobrepõem, desde esse relato inaugural até os mais atuais, e - por que não? - afetarão os próximos discursos.

Nesse sentido Beatriz Sarlo (2007), assim como Maurice Halbwachs (1990), reconhece a importância dos relatos para a composição da memória social. Sarlo (2007) cita a guinada subjetiva, ocorrida nas décadas de 1970 e 1980, como o momento em que os testemunhos começaram a ser valorizados para o estudo do passado. A autora cita como fatores que motivaram a utilização dos relatos a "verdade" abrigada na rememoração da experiência, a revalorização da primeira pessoa como ponto de vista e a reivindicação de uma dimensão subjetiva.

Outro aspecto apontado por Sarlo (2007) para o interesse nos testemunhos é ampliar o olhar dos historiadores e cientistas. Segundo ela, é necessário valorizar os detalhes, a originalidade, a exceção à regra e as curiosidades que já não se encontram no presente.

A autora ainda explica que a escuta desses novos sujeitos exige a adoção de novos métodos e a observação sistemática dos "discursos de memória", como diários, cartas e conselhos. No entanto, o uso de objetos históricos, o "dever de memória", induz uma relação afetiva com o passado pouco compatível com o distanciamento característico ao ofício do historiador.

Quanto às vantagens da utilização do relato para a memória social, Sarlo (2007) novamente lembra que o relato testemunhal existe em meio a uma massa de materiais escritos contemporaneamente aos fatos e que funcionam como fontes ricas que não devem ser deixadas de lado.

Priscila Perazzo (2015), por sua vez, defende a validade da memória social como metodologia de pesquisa, uma vez que as narrativas orais não são menos verdadeiras, nem menos ficcionais do que histórias oficiais. Afinal, cada sujeito narra a sua história a partir da sua própria subjetividade.

A autora alerta que trazer a primeira pessoa do relato para a ciência exige novos métodos para análise e interpretação de relatos de memória.

Para que nós, pesquisadores, não sejamos reféns das intenções do narrador, é preciso que se constitua um método de interpretação desses dados, pautado no conhecimento das formas como se dão as narrativas, das escolhas que o narrador pode fazer para selecionar o que contar, advindos da compreensão da cultura, da memória e do imaginário desse sujeito. (PERAZZO, 2015: 126)

Segundo Perazzo (2015), adotando esses cuidados ao trabalhar com testemunhos, estaremos trazendo para a ciência as dimensões dos sentidos, dos sentimentos e das mentalidades que antes pertenciam apenas aos domínios dos relatos literários e das crônicas. 


\section{Memória, dossiê e rastros digitais}

Apresentados esses conceitos preliminares e considerando que os relatos das viajantes selecionadas podem ser narrativas de memória, lançamos alguns questionamentos que este texto pretende ajudar a elucidar: quais são as características dessas narrativas quando "depositadas" em plataformas virtuais como o Facebook? Poderíamos dizer que as plataformas virtuais correspondem a um espaço de preservação e divulgação da memória das pessoas?

Para discutirmos as memórias registradas nas mídias digitais, mostra-se fundamental abordarmos o que dizem alguns teóricos acerca dos "rastros digitais", isto é, das representações que deixamos na rede mundial de computadores. John Palfrey e Urs Gasser (2011) dão a esse conjunto de informações o nome de "dossiê digital". Essas informações podem ser classificadas em dois tipos: as de caráter público, localizáveis no Google, por exemplo, por qualquer usuário; e as informações sigilosas, tais como números de telefone e documentos pessoais.

O problema desses rastros, na visão dos autores, relaciona-se tanto ao rápido crescimento dos dossiês digitais, quanto às decisões sobre o que fazer com as informações pessoais pelos que as detêm.

Analisando o Facebook, nosso objeto em questão, podemos traçar um paralelo com as questões acima. Um post escrito pelas viajantes pode ser posteriormente apagado, por arrependimento ou qualquer outra motivação. Entretanto, ele pode ter sido compartilhado por algum seguidor da página e visualizado por várias pessoas antes de ser deletado, por exemplo. Dessa forma, os percursos das narrativas em análise são totalmente imprevisíveis e desconhecidos. Ou ainda, mesmo quando não apagados, os posts podem ser "printados" e replicados na linha do tempo de outras pessoas em situações, contextos e significados completamente alheios aos das autoras.

Jeanne Marie Gagnebin (2006) compartilha a mesma preocupação citando a não intencionalidade dos rastros, e também aponta para uma ligação entre rastro e memória. Segundo ela, assim como ocorre com as nossas lembranças, nem sempre os rastros são os que queremos guardar, mas apenas o que restou de vestígios de uma determinada ação. Para a autora, a memória vive uma tensão entre presença e ausência desses rastros, em que a presença indica a conservação da memória e, a ausência, o processo de esquecimento:

Agora a escrita não é mais um rastro privilegiado, mais duradouro do que outras marcas da existência humana. Ela é rastro, sim, mas no sentido preciso de um signo ou, talvez melhor, de um sinal aleatório que foi deixado sem intenção prévia, que não se inscreve em nenhum sistema codificado de significações, que não possui, portanto, referência linguística clara. O detetive, o arqueólogo e o psicanalista, esses primos menos distantes do que podem parecer à primeira vista, devem decifrar não só o rastro na sua singularidade concreta, mas também adivinhar o processo, muitas vezes violento, de sua produção involuntária. Rigorosamente falando, rastros não são criados - como são outros signos culturais e linguísticos -, mas sim deixados ou esquecidos. (GAGNEBIN, 2006: 113)

Quanto ao destino e à perenidade das nossas narrativas de memória nas plataformas on-line, Canavilhas (2004) expõe a fragilidade do suporte midiático que as acolhe. Ele pondera, por exemplo, que enquanto o papel dura séculos, se bem conservado, os formatos digitais tornam-se obsoletos em 10 ou 20 anos.

Apontamos essas reflexões como alguns dos desafios contemporâneos de as nossas memórias estarem em rede, acrescidos pela ameaça de os nossos rastros digitais estarem à disposição na rede mundial de computadores. Concordamos com Turkle (2006: 291) quando afirma que é um erro falar que a vida real é distinta da virtual, como se fossem independentes. Segundo o autor, o que somos na internet não difere do que somos no nosso cotidiano: comunicamos ao outro o que queremos que ele saiba, fazemos um recorte, assumimos uma persona. Tal fenômeno ocorre igualmente no mundo físico. 
Ao pensarmos nas fanpages das viajantes, verificamos que as postagens das jovens relatando seu dia a dia de viagem apresentam implicações como as definidas por Halbwachs (1990), ou seja, demonstram características das memórias individuais de suas viagens por meio dos relatos de suas vivências na estrada, sendo também memórias coletivas por estarem em diálogo com os seguidores das páginas, para quem escrevem:

\begin{abstract}
Não é suficiente reconstituir peça por peça a imagem de um acontecimento do passado para se obter uma lembrança. É necessário que esta reconstrução se opere a partir de dados ou de noções comuns que se encontram tanto no nosso espírito como no dos outros, porque elas passam incessantemente desses para aquele e reciprocamente, o que só é possível se fizeram e continuam a fazer parte de uma sociedade. (HALBWACHS, 1990: 34)
\end{abstract}

Assim como a carta de Pero Vaz de Caminha, guardadas as devidas proporções, ao escreverem, as viajantes também colaboram para a composição da memória social de seus seguidores. Um fã da página que, por exemplo, nunca tenha ido à Colômbia, construirá parte do seu imaginário sobre o país a partir do que lê nos relatos das fanpages.

É importante ressaltar que os rastros deixados pelas viajantes seguem um percurso de transmutação até mais intenso do que o dos antigos relatos, por serem permanentemente entrecruzados por outras narrativas. Entendemos por transmutação o fenômeno que colabora para a formação dos gêneros complexos a partir dos gêneros primários que, ao se transmutarem de uma esfera para outra, geram novos gêneros com um estilo semelhante ao domínio discursivo que os absorveu. No caso das jovens viajantes, as postagens nas fanpages correspondem aos antigos diários de papel.

Não só cada gênero está em incessante alteração; também está em contínua mudança seu repertório, pois, à medida que as esferas de atividade se desenvolvem e ficam mais complexas, gêneros desaparecem ou aparecem, gêneros diferenciamse, gêneros ganham um novo sentido. Com o aparecimento da internet, novos gêneros surgem: o chat, o blog, o e-mail, etc. (FIORIN, 2008: 65)

Reconhecemos que o processo de registro das narrativas de memórias de viagem é dinâmico e interativo nas mídias digitais, mais especificamente, nas fanpages de viajantes disponíveis no Facebook. Cabe-nos, agora, refletir sobre o consumo dessas memórias.

\title{
Consumo de narrativas de memória de viajantes no Facebook
}

Tomando as postagens como uma memória do passado, um registro de um tempo pretérito, Thiago de Oliveira (2013) tece uma reflexão sobre o consumo do culto à memória nas mídias sociais, o que pode ser percebido também no Facebook. Ele cita como exemplos os usuários "curtirem", compartilharem e criarem debates em torno de registros antigos de suas histórias de vida na antiga rede social Orkut, lembrada por usuários do Twitter por meio da hashtag \#temposdoorkut.

A partir das ideias apresentadas e analisando o caso específico das memórias "depositadas" virtualmente, o que podemos acrescentar é que, por serem páginas públicas e com seguidores, o lembrar ganha um caráter intencional, seja para quem as produz, seja para quem as consome. Afinal, não se trata mais de alguém desavisado que segue um caminho aleatório para perseguir rastros, pois embora estes surjam a qualquer momento, podem ser descontinuados, desde que recusemos seguir os caminhos que nos apontam: cliques em determinados links, adesão a outras redes sociais, compartilhamentos, curtidas ou comentários para ou de outras pessoas. O contrário ocorre quando quem detém uma fanpage retorna e retoma suas postagens antigas como um velho álbum de fotografias. 
A posição do tempo ocupada pelas memórias reproduzidas nas mídias digitais é outro aspecto discutido por Canavilhas (2004). O autor explica que nelas ocorre a "compressão" do tempo: quando usuários postam fotos e textos em "tempo real" no Facebook, seus seguidores produzem e também postam esses mesmos eventos simultaneamente. Assim, as narrativas tornam-se um registro sobre o momento instantâneo para um presente também instantâneo, quase como que um presentepassado ou um presente-presente.

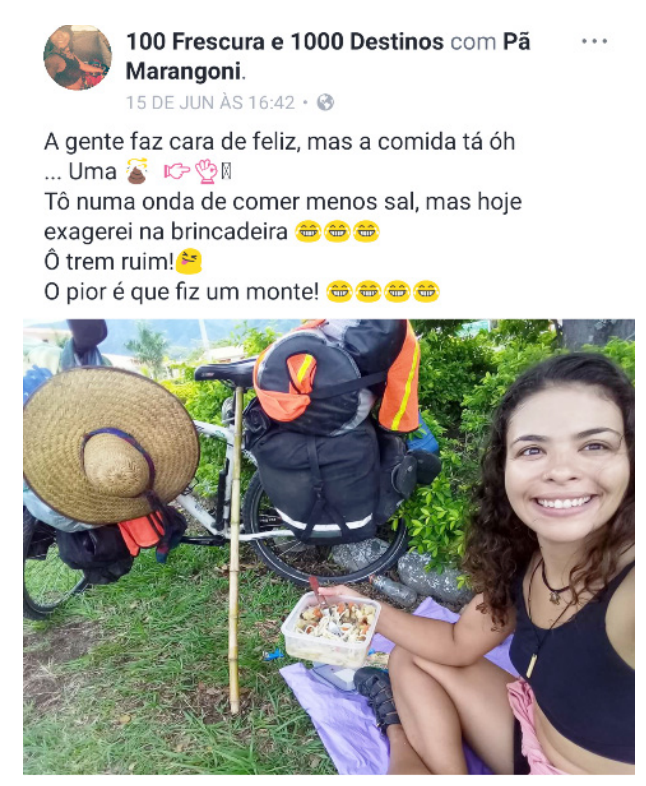

Figura 1: Postagem na qual a viajante Pâmela Marangoni apresenta um detalhe do seu cotidiano no mesmo momento em que ele está ocorrendo. Fonte: 100 Frescura e 1000 Destinos, 2017.

Entretanto, também se percebem recordações do passado-passado, quando as postagens mencionam eventos acontecidos algum tempo antes, articulando-os com o presente, como ocorre na postagem do dia 20 de abril de 2016 da viajante Dwanne Almeida.

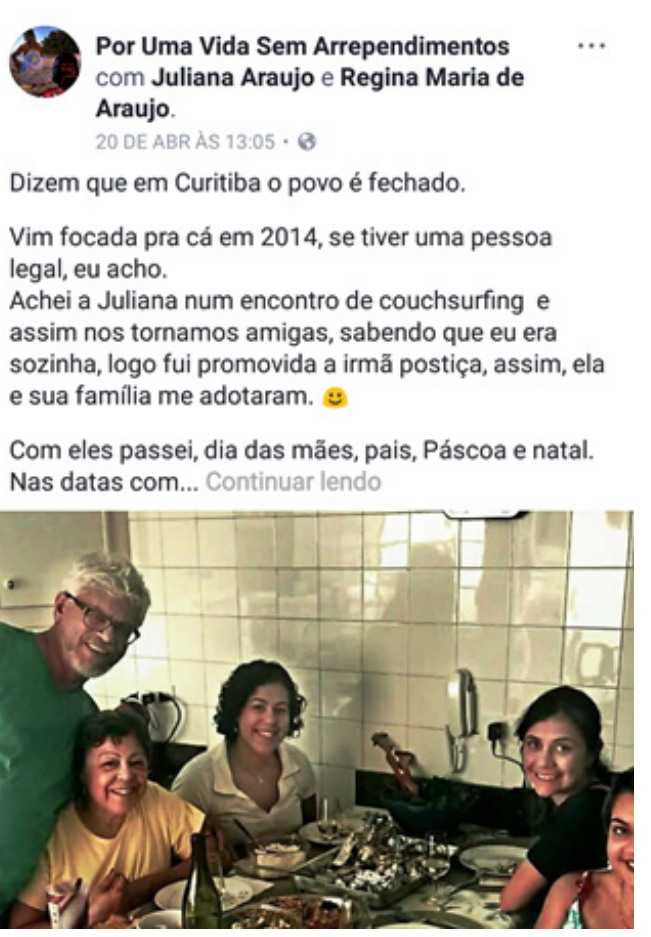

Figura 2: Post no qual a viajante Dwanne Almeida relata como uma experiência passada anteriormente ainda faz sentido em sua vida atual. Fonte: Por Uma Vida Sem Arrependimentos, 2016.

Esse post é uma memória coletiva não apenas na sua construção, mas também na sua interpretação, pois por meio de postagens como essa são conquistadas 
hospedagens gratuitas e outros benefícios, como a amplificação das redes de relacionamento virtual e real. Utilizar o Facebook como espaço para o "depósito" de memórias é um recurso ao alcance de praticamente todos, conforme Marcos Palácios (2010).

\begin{abstract}
A comunicação rizomática e a liberação do polo emissor multiplicaram - a perder de vista - os lugares de memória em rede, tornando cada usuário um potencial produtor de memórias, de testemunhos. É evidente que pelo menos parte de tais registros sobreviverão a seus produtores, como ao comunicador neolítico sobreviveram as marcas gravadas nas pedras ou as pinturas rupestres. (PALACIOS, 2010: 9)
\end{abstract}

Embora seja possível a todos os usuários produzirem relatos de viagens virtuais no Facebook, poucos atingem grau de notoriedade, já que essas memórias precisam ser consumidas por aqueles que frequentam a plataforma.

Assim sendo, é importante lembrarmos que nem a todos os relatos despertam interesse. Michael Pollak (1989), cuja obra é posterior à primeira edição de $A$ Memória Coletiva, de Maurice Halbwachs (publicada postumamente em 1950), compartilha a ideia proposta pelo seu conterrâneo morto pelos nazistas: para que a nossa memória se beneficie da do outro, é necessário haver uma espécie de conciliação envolvendo as memórias coletivas e as individuais:

Para que nossa memória se auxilie com a dos outros, não basta que eles nos tragam seus depoimentos: é necessário ainda que ela não tenha cessado de concordar com suas memórias e que haja bastante pontos de contato entre uma e as outras para que a lembrança que nos recordam possa ser reconstruída sobre um fundamento comum. [...] É necessário que esta reconstrução se opere a partir de dados ou de noções comuns que se encontram tanto no nosso espírito como no dos outros. (HALBWACHS, 1990: 34)

Ou seja, os relatos das jovens viajantes precisam despertar a atenção dos usuários da rede social Facebook. No caso das viajantes, a relação entre quem escreve a história e quem a lê é virtual e, portanto, ao contrário da "vida real", elas obtêm respostas numéricas acerca do interesse que suas memórias provocam, por meio do número de "curtidas" ou de compartilhamentos.

Pouco espaço é dedicado a detalhes ruins das viagens, o que pode representar uma forma de garantir a audiência da página e a solidificação da identidade de viajantes felizes. Afinal, como afirmam muitos teóricos contemporâneos, "a felicidade tornouse um 'imperativo', uma mistura de dever e direito que pesa sobre os ombros de homens e mulheres do século XXI" (CAZELOTO, 2011: 171). Mais ainda: tornou-se um modelo de negócios. Novamente, tomemos a análise de Edilson Cazeloto:

\begin{abstract}
A felicidade sustenta e legitima um mercado cada vez mais amplo (livros de autoajuda, palestras, terapias, medicamentos, produtos de beleza, moda etc.), sintoma da expansão tendencialmente infinita da lógica da mercadoria. A busca pela felicidade é um investimento que transfere valor à mercadoria. Como consequência deste primeiro ponto surge outra constatação: a felicidade foi privatizada, retirada da esfera da socialidade para o campo da ação individual. Mais do que isso: ela foi reduzida a uma "interioridade pura": ser feliz relacionase, na cultura contemporânea, a ser "autônomo", ou seja, a felicidade é um estado interior que se conquista independentemente das circunstâncias sociais ou políticas. (CAZELOTO, 2011: 173)
\end{abstract}

As mochileiras "trabalham" em suas redes fornecendo dicas de viagem, fotos dos lugares, tirando dúvidas etc. Suas ações são épicas e, claro, individuais, mas 
diferentemente dos grandes heróis míticos, mostram que todos os objetivos são acessíveis, desde que se tenha coragem e humildade. A contrapartida, isto é, o "pagamento" dos seguidores, se dá por meio da oferta de hospedagem gratuita, carona e, ocasionalmente, "vaquinhas" (pessoas que se unem para contribuir com pequenas quantias em nome de uma causa). Foi dessa forma, por exemplo, que Pâmela Marangoni conseguiu custear a sua ida de avião ao México.

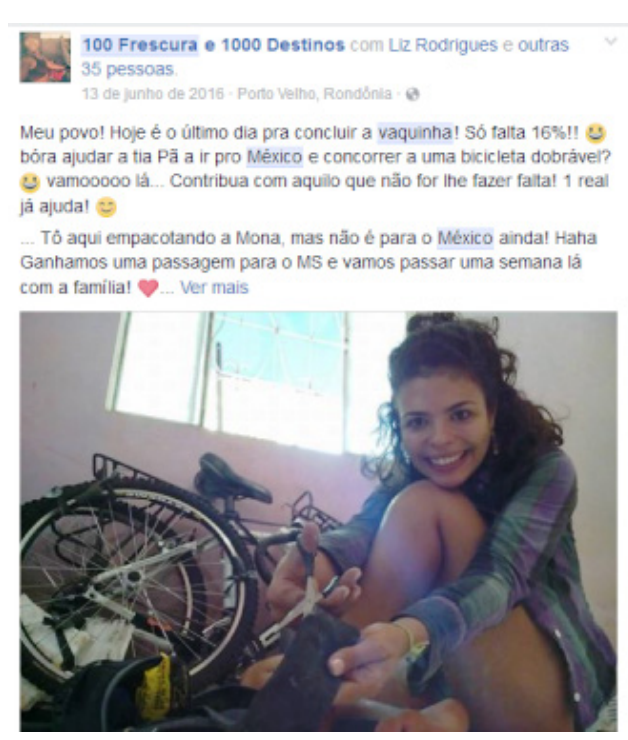

Figura 3: Postagem na qual a viajante Pâmela Marangoni reforça o pedido de auxílio financeiro para compra de uma passagem aérea para o México. Fonte: 100 Frescura e 1000 Destinos, 2016.

A estreita interação entre real e virtual, a simultaneidade entre a produção dos relatos, seu consumo e o evento acontecido, bem como o fomento ao universo colaborativo são algumas das características que o Facebook modela. Por isso, podemos começar a concluir que essas memórias, mesmo quando tratam da vida de uma viajante em específico, pertencem a múltiplas autorias. Assim como os antigos viajantes exploradores que, ao retornarem para suas cidades de origem, prestavam contas aos patrocinadores, apresentando seus relatos e objetos recolhidos, nossas "heroínas" contemporâneas, com suas mochilas e um pouco (às vezes nada) de dinheiro, fazem o mesmo com seus seguidores, uma vez que são eles que atribuem prestígio às suas fanpages.

Viajantes e seguidores se influenciam mutuamente: enquanto os segundos buscam relatos emocionantes, ideias e dicas para cumprirem sua meta de felicidade, as primeiras necessitam viabilizar a produção de suas memórias em suas fanpages, enquanto viajam, para levantar fundos ou outro tipo de auxílio.

\section{Considerações finais}

Observamos que as tecnologias de comunicação trouxeram novas plataformas para exposição e depósito de narrativas, o que possibilitou a mudança na forma de registro das memórias, a facilitação da comunicação entre as pessoas e a ampliação exponencial da capacidade de conexão.

Os que optam pelos estudos da memória, diferentemente de historiadores tradicionais, valorizam a expressão da subjetividade, uma vez que não se está em busca da "verdade", mas de narrativas que estão em circulação e que, como vimos, afetam nosso desejo de consumir felicidade.

Outra reflexão que nos parece viável, é que se no futuro os registros disponíveis nas redes sociais não se perderem, eles constituirão um rico material a ser estudado pelos que pesquisam o passado, considerando a pluralidade de discursos neles contida.

As interações entre as autoras das fanpages e seus seguidores geram repercussões e questões de interesse comum na rede. Consequentemente, um determinado 
nicho de consumidores também está em formação: os que viajam seguindo certos padrões de comportamento, entre eles, o baixo orçamento e a alta troca de informações.

Na rede surgem a cada dia mais maneiras de monitorar, classificar, tipificar e mensurar essas interações. Assim, há ônus e bônus correlatos: o rastro contemporâneo da memória social nos traz o paradoxo quanto à sua durabilidade, à sua perenidade e à preservação da individualidade dos usuários, sejam eles produtores de fanpages ou seus seguidores. Por outro lado, temos acesso a informações instantaneamente, sem intermediações ou pagamentos formais. Também nos perguntamos: qual o valor agregado ou despendido nessas interações? Qual memória será esquecida ou preservada?

A busca por essas respostas nos parece ainda um desafio, uma vez que estamos tratando de um fenômeno recente, no qual todos que se conectam na rede saem afetados pelas narrativas que ali encontram, mesmo quando não estão procurando por elas.

\section{Referências}

100 FRESCURA E 1000 DESTINOS, [S.I.], 2013. Facebook. Disponível em: <https:// goo.gl/LwGiiC>. Acesso em: 7 fev. 2018.

BENJAMIN, W. O narrador: considerações sobre a obra de Nikolai Leskov. In: Magia e técnica, arte e política. Ensaios sobre literatura e história da cultura. 7. ed. São Paulo: Brasiliense, 1994. (Obras escolhidas, v. 1).

CANAVILHAS, J. A internet como memória. BOCC: Biblioteca On-line de Ciências da Comunicação. [S.I.], 2004. Disponível em: <https://goo.gl/1LKxGu>. Acesso em: 5 maio 2017.

CASTRO, S. A carta de Pero Vaz de Caminha: o descobrimento do Brasil. Porto Alegre: L\&PM, 2003.

CAZELOTO, E. Ubuntu e a felicidade técnica. Revista Galáxia, São Paulo, n. 21, p. 171-175, jun. 2011.

FIORIN, J. L. Introdução ao pensamento de Bakhtin. São Paulo: Ática, 2008.

GAGNEBIN, J. M. Lembrar escrever esquecer. São Paulo: Editora 34, 2006.

HALBWACHS, M. A memória coletiva. Tradução Laurent Leon Schaffter. São Paulo: Revista dos Tribunais, 1990.

JUNQUEIRA, M. A.; FRANCO, S. M. S. (Orgs.). Cadernos de Seminários de Pesquisa - Volume II. São Paulo: USP-FFLCH-Editora Humanitas, 2011.

OLIVEIRA, T. M. Narrativas do passado no Facebook: consumo de temas de história e memória na fanpage "Fortaleza Nobre". In: ENCONTRO NACIONAL DE HISTÓRIA DA MÍDIA, 9., 2013, Ouro Preto. Anais eletrônicos... Ouro Preto: UFOP, 2013. Disponível em: <https://goo.gl/MMFvLw>. Acesso em: 8 maio 2017.

PALÁCIOS, M. Convergência e memória: jornalismo, contexto e história. Matrizes, São Paulo, v. 4, n. 1, p. 37-50, 2010.

PALFREY, J.; GASSER, U. Nascidos na era digital: entendendo a primeira geração de nativos digitais. Porto Alegre: Artmed, 2011.

PERAZZO, P. F. Narrativas orais de histórias de vida. Comunicação \& Inovação, v. 16, n. 30, p. 121-131, jan.-abr. 2015. Disponível em: <https://goo.gl/e9aswJ>. Acesso em: 10 maio 2017. 
POLLAK, M. Memória, esquecimento, silêncio. Estudos Históricos, Rio de Janeiro, v. 2, n. 3, p. 3-15, 1989.

POR UMA VIDA SEM ARREPENDIMENTOS, [S.I.], 2015. Facebook. Disponível em: <https://goo.gl/MV8r2K>. Acesso em: 7 fev. 2018.

SARLO, B. Tempo passado: cultura da memória e guinada subjetiva. São Paulo: Companhia das Letras, 2007.

SCHEMES, E. F. Oswaldo Cabral na "Terra da liberdade": relato de uma viagem na vigência da política de boa vizinhança. 2013. 134 p. Dissertação (Mestrado) Universidade Federal de Santa Catarina, Centro de Filosofia e Ciências Humanas, Programa de Pós-Graduação em História, Florianópolis, 2013.

TURKLE, S. A memória na tela. In: CASALEGNO, F. Memória cotidiana: comunidade e comunicação na era das redes. Porto Alegre: Sulina, 2006. 